\title{
Esquizoanálisis y necropoder: la representación del (narco) capitalismo y la violencia en la narconarrativa mexicana reciente.
}

Schizoanalysis and necropower: the representation of (narco) capitalism and violence in the recent Mexican narrative.

DOI: $10.32870 /$ sincronia.axxv.n79.15a21

\author{
Gerardo Castillo-Carrillo * \\ Departamento de Humanidades. Universidad Iberoamericana-Puebla (MÉXICO) \\ CE: gerardocastilloc@hotmail.com / ID ORCID: 0000-0002-8167-1169
}

Esta obra está bajo una Licencia Creative Commons Atribución-NoComercial 4.0 Internacional

\begin{abstract}
* Doctor en Literatura Hispanoamericana (Universidad Autónoma de Puebla). Actualmente es profesor de la Maestría en Literatura Aplicada y de la Licenciatura en Literatura y Filosofía de la Universidad Iberoamericana-Puebla. Asimismo, colabora como docente en el programa de Argumentación y Escritura Académica en la Universidad de las Américas-Puebla (UDLAP). Ha impartido diversos talleres de apreciación literaria, de modalidades discursivas y de didáctica del ensayo. Las líneas de investigación que trabaja son Estudios Culturales, Narcoficción y Corrientes escénicas del siglo XXXXI
\end{abstract}

Recibido: $30 / 09 / 2020$

Revisado: $22 / 10 / 2020$

Aprobado: 10/11/2020

\section{RESUMEN}

En el presente escrito, bajo los preceptos de esquizoanálisis (Deleuze \& Guattari) y necropoder (Mbembe), se revisará que la novela del narcotráfico se centra en reproducir dos contantes discursivas expuestas de manera consuetudinaria por las instituciones oficiales (gobierno, medios de comunicación, industria del entretenimiento, etcétera): el (narco)capitalismo y la violencia. Como propósito central, analizaré de qué manera en esta narrativa el terrorismo sistemático ejercido por los cárteles de la droga a través de su poder económico, quienes al proceder como grandes corporativas trasnacionales, pueden corromper todos los estratos sociales, erigiéndose, así como el socius supremo; evidenciando de esta manera que estas organizaciones delictivas fragmentan, controlan y trasgreden el espacio público.

Palabras Clave: Narconarrativa. Capitalismo Gore. Máquina Despótica. Necropolítica. Biopoder. 


\section{ABSTRACT}

In this writing, under the precepts of schizoanalysis (Deleuze \& Guattari) and necropower (Mbembe), it will be reviewed that the drug trafficking novel focuses on reproducing two discursive constants exposed in a customary way by official institutions (government, media, entertainment industry, etc.): (narco) capitalism and violence. As a central purpose, I will analyze in what way in this narrative the systematic terrorism exercised by the drug cartels through their economic power, who, acting as large transnational corporations, can corrupt all social strata, thus establishing themselves as the supreme socius; thus evidencing that these criminal organizations fragment, control and transgress public space.

Keywords: Narconarrative. Gore Capitalism. Despotic Machine. Necropolitical. Biopower.

\section{Planteamiento inical}

En las últimas décadas, la literatura mexicana ha registrado una abundante producción de narrativa con temática narco, distintos escritores principalmente del norte del país (Élmer Mendoza, Daniel Sada, Víctor Hugo Rascón Banda, César López Cuadras, Hilario Peña, Heriberto Yépez, entre otros.) han explorado esta problemática criminal desde distintos ángulos: violencia, capitalismo gore, corrupción, sicariato, necropolítica, etcétera. Por tal motivo, considero pertinente revisar en algunas novelas representativas de esta vertiente, la construcción literaria sobre este tópico bajo la luz de dos conceptos filosóficos: el ezquizoanálisis y el necropoder.

De este modo, apoyándome en la teoría del esquizoanálisis de Gilles Delauze y Félix Guattari (2002), así como en los conceptos de biopoder/necropolítica de Achille Mbembe (2006), demostraré que la narco-narrativa, a través de sus personajes y hechos, representa la violencia como un acto instrumental que desestabiliza el orden social; en consecuencia, en distintas novelas se expone que los cárteles de la droga operan como entidades con derecho a matar, los cuales por ende aniquilan todo aquello que imposibilita su expansión geográfica y económica. Para comprobar lo anterior, centraré mi análisis en las obras, de esta corriente literaria, que con más claridad ejemplifican mis planteamientos: El vuelo de Sergio González Rodríguez (2018); Fiesta en la Madriguera de Juan Pablo Villalobos (2010); Contrabando de Víctor Hugo Rascón Banda (2008); 
Hielo negro de Bernardo Fernández (2011); La Prueba del ácido de Élmer Mendoza (2010), y Conspiración de Víctor Ronquillo (2011).

\section{Dos máquinas despóticas: Esquizoanálisis y Necropoder}

En primer orden explicaré los conceptos básicos que conforman el esquizoanálisis. Gilles Deleuze y Félix Guattari, tanto en El anti-Edipo (1985) como en Mil mesetas: capitalismo y esquizofrenia (2002), bajo el concepto de esquizoanálisis, proponen una nueva forma de estudiar el inconsciente ${ }^{1}$ y el capitalismo. Con este nuevo método, el objetivo central será realizar una práctica crítica sobre el funcionamiento de los flujos energéticos, dentro de un contexto social específico. Asimismo, aseveran que hay máquinas (territoriales, despóticas o capitalistas) que controlan o codifican los flujos para regularlos, homogeneizarlos y reprimirlos.

De este modo, la máquina capitalista opera su territorio de forma desorganizada, caótica e irracional, incorpora otros sistemas que no puede controlar, se apropia de ellos y los hace parte de su propio orden. En síntesis, se conduce como un esquizofrénico que se reterritorializa para bloquear o interrumpir movimientos de desterritorialización: "El capitalismo universal y en sí no existe, el capitalismo está en la encrucijada de todo tipo de formaciones, siempre es por naturaleza neocapitalismo; desgraciadamente inventa una versión oriental y otra occidental, y la transformación de ambas" (Deleuze \& Guattari, 2002, p. 24). Ambos autores conciben al capitalismo como un sistema dominación hegemónico, en el que las instituciones (bancarias, estatales, mediáticas) validan, controlan y propagan esta práctica. Ante tal disyuntiva, Deleuze y Guattari (2002) consideran que mediante el esquizoanálisis se puede comprender el funcionamiento de la maquinaría social y capitalista.

El esquizoanálisis, de acuerdo con Deleuze y Guattari (2002), se compone de tres aspectos o líneas: molar, molecular y fuga. La línea molar se refiere a entidades establecidas o fijas como el

\footnotetext{
${ }^{1}$ Deleuze y Guattari consideran que el psicoanálisis tiene un margen de acción reduccionista y dictatorial, que constriñe al inconsciente a estructuras cerradas; en cambio, el esquizoanálisis propone una apertura finita de posibilidades (rizoma) que conlleva a un estado absolutamente diferente al inconsciente y posibilita otras formas de comprensión.
} 
Estado, la familia, la Iglesia, etcétera, los cuales en sí mismos representan dispositivos de poder, caracterizados por instituir códigos y territorializar el espacio que le corresponde. Dentro de este flujo (el molar) existen tres segmentos: el binario, representado por oposiciones duales como hombre-mujer o adulto-niño; el circular, constituido de lo particular a lo universal: barrio, ciudad, país, continente, mundo; y el lineal, visto como el inicio y fin de un ciclo: escuela, profesión, trabajo, matrimonio.

Por su parte, la línea molecular constituye desequilibrios, pequeñas diferencias o variables con lo molar; entre ambas coexiste una relación de inestabilidad, pero no de ruptura, funcionan de distinto modo. En suma, son multiplicidades rizomáticas ${ }^{2}$ que adquieren autonomía sin estar sujetas a entidades superiores (Deleuze \& Guattari, 2002).

Por último, la línea de fuga o de desterritorialización, según los autores, se caracteriza por el devenir continuo, surge como una ruptura global, como un segmento irreversible que borra todo espacio, territorio y pasado posible. Está visualizado como la abolición y la destrucción que no permite recuperar los códigos anteriores; no obstante, a pesar de la fractura termina convirtiéndose en un segmento molar (Deleuze \& Guattari, 2002). Precisamente este último elemento presenta las mismas características de operación que el crimen organizado, el cual después de desestabilizar todos los órdenes legales, termina por institucionalizarse, por ejercer control y establecerse como una entidad inmutable, como un bloque molar.

Por su parte, el filósofo camerunés Achille Mbembe (2006) toma como punto de partida la teoría foucaultiana de biopoder ${ }^{3}$ para emitir la noción de necropolítica, la cual, según explica, consiste en la gubernamentalidad de la muerte, en la que los sujetos se convierten en productos de

\footnotetext{
${ }^{2}$ El concepto rizoma, según sus autores, no tiene ni principio ni fin, crece y se desborda en múltiples direcciones. Está conformado de líneas de fuga, segmentas o estratificadas conectadas con cualquier punto. Se contrapone a cualquier estructura que se caracterice por establecer puntos y posiciones finitas. Es ante todo modificable, con un sinfín de entradas y salidas, siempre en continuo movimiento.

${ }^{3}$ Michel Foucault (2000) explica los diversos mecanismos y formas en las que se institucionaliza el poder. En ellas, de acuerdo con Foucault, siempre hay dinámicas de dominación y sometimiento. Uno de los elementos centrales para ejercer esta sumisión es precisamente el discurso, aspecto mediante el cual se puede establecer un sinfín de bloques informativos que reproducen enunciados que de manera indistinta pueden ser falsos o verdaderos. Los aparatos económicos y políticos son quienes mayor influencia ejercen socialmente, acorde con sus intereses.
} 
desecho. El capitalismo, manteniendo este orden, reduce a simple objeto mercantil a la población, al considerar que las personas ya no son irremplazables y pueden ser fácilmente sustituibles. En las sociedades del control necropolítico, los sujetos se reducen solo a cuerpos-máquina productivos y redituables ante una economía perversa que prevalece por encima de cualquier otra lógica.

El término necropolítica, acorde con Mbembe (2006), se refiere a todas aquellas personas que viven es un estado de indefensión absoluta, marginadas y carentes de bienes económicos. "Seres invisibles" que habitan lugares atípicos como la calle, los puentes, las estaciones de tren abandonadas, lotes baldíos, etc. Estas comunidades silenciosas son eliminadas si problema por un ente intangible denominado necropoder. En este espacio el narcotráfico normaliza la muerte; es decir, se configura una significación de la vida como desechable o superflua. De esta forma, esta categoría me permitirá evaluar las bases pragmáticas que los cárteles de la droga implementan (violencia, explotación, marginación) y de qué forma son expuestos -en nuestro corpus de estudio- estos mecanismos, que Mbembe denomina como lógicas del poder de la muerte.

Bajo este contexto, el sujeto contemporáneo queda fragmentado, descentrado, reducido a un simple dato estadístico. Ante este aniquilamiento, el hombre también liquida sus patologías (neurosis, delirios de grandeza, mitos), quedan sólo como parte del pasado. El mundo queda bajo el resguardo de las entidades económicas, que al parecer no representan ningún peligro, pero sí son una amenaza contante por el control que ejercen sobre las sociedades actuales y la negación de alguna posible salida de este yugo capitalista. En este sentido Mbembe (2006) asevera: "el Estado no reconoce ninguna autoridad que le sea superior en el interior de sus fronteras. Por otro lado, el Estado emprende la tarea de «civilizar» las formas de asesinar y de atribuir objetivos racionales al acto mismo de matar" (p. 38).

De acuerdo con las consideraciones anteriores, las narcoficción mexicana indistintamente plantea que los cárteles de la droga son segmentos molares que controlan y administran el terror y la muerte. Bajo su lógica se genera un estado de necropoder, en el que las víctimas principales son aquellos que trasgreden sus intereses monetarios. Esta economía criminal funciona, como ya apunté, bajo una lógica del desecho. De este modo, la máquina capitalista opera su territorio de 
forma violenta, caótica e irracional, incorpora otros sistemas que no puede controlar, se apropia de ellos y los hace parte de su propio orden. Se conduce-en términos de Deleuze y Guattari (2002)como un esquizofrénico que bloquea o interrumpe cualquier movimiento de territorialización.

\section{El (narco) capitalismo y la violencia en la narconarrativa mexicana}

Ahora corresponde revisar, en nuestro corpus de análisis, cómo a través de los recursos monetarios se puede ejercer el dominio y la expansión territorial; este hecho demuestra que el capitalismo es un complejo proceso político-social que está en una constante recodificación, el cual conlleva, retomando a Deleuze y Guattari (2002), a producir, a innovar, sustituir, crear y destruir a través de la intimidación y la fuerza. Esta singular vorágine económica es un rasgo característico de la narconarrativa, así se puede observar en la novela Hielo negro en palabras de Lizzy Zubiaga, jefa del cártel de Constanza:

Cuando era niña tenía que explicar la opulencia en la que vivíamos, contrastada con el rampante mal gusto de mi apá diciendo que éramos comerciantes. Y eso era el desgraciado. Una especie de bodeguero de drogas. Yo pienso en mí misma como una empresaria global. Por eso la misión de mi corporación (no cártel, por favor) es dotar de nuevas experiencias y diversificar los productos disponibles para los más selectos psiconautas del mundo. (Fernández, 2011, pp. 177-178. Las cursivas son mías).

En el ejemplo anterior, para Lizzy, el tráfico de drogas representa un modelo capitalista de producción que desarrolla nuevos valores y patrones socio-culurales globales, propiciando una reterritorialización económica, la cual cuestiona el funcionamiento y la lógica del propio capitalismo. En este sentido, es pertinente enfatizar que el carácter dinámico y contradictorio del libre mercado provoca el debilitamiento del Estado y la acumulación material como único plusvalor, este último aspecto se ve reflejado claramente en la novela Fiesta en la madruguera, en voz de su narrador, un infante de escasos diez años, Tochtli: 
Yolcaut y yo somos dueños de un palacio, y eso que no somos reyes. Lo que pasa es que tenemos mucho dinero. Muchísimo. Tenemos pesos que es la moneda de México. También tenemos dólares, que es la moneda del país de los Estados Unidos. Y también tenemos euros, que es la moneda de los países y estados de Europa. Me parece que tenemos miles de millones de los tres tipos, aunque los que más nos gustan son los billetes de cien mil dólares. Y además del dinero tenemos las joyas y los tesoros. $Y$ muchas cajas fuertes con combinaciones secretas (Villalobos, 2010, p.19).

De este modo, como se puede observar-en voz de Tochtli- el capitalismo se expande como una nueva forma de poder que propicia una cadena de flujos: monetarios, acumulativos, de propiedad, etc., haciendo que se comporte de manera ilógica y anárquica. Ante tales condiciones, la máquina capitalista transformará su lógica y establecerá un nuevo orden político, en el que el Estado es cómplice y subordinado, así se observa también en Fiesta en la madrigiuera:

Hoy conocí a la persona catorce o quince que conozco y era un político llamado el gober. Vino a cenar a nuestro palacio [...] El gober es un señor que se supone que gobierna a las personas que viven en un estado. Yolcaut dice que el gober no gobierna a nadie, ni siquiera a su puta madre. (Villalobos, 2010, p. 26).

El narcotráfico al tener una creciente participación e injerencia en el sistema de poder, motiva la ausencia de límites porque es capaz de añadir nuevos axiomas y códigos que no cesan de ser producidos por el constante flujo del [narco] capitalismo.

En consecuencia, el capitalismo al desterritorializar y reterritorializar transforma y modifica el mapa geopolítico, porque como anotan Deleuze y Guattari (2002): “es un modo de evaluación y medio técnico de control de los agenciamientos de potencia y de sus formaciones de poder correspondientes" (p. 102). De esta forma, la narco-economía participa y penetra la esfera política, inicialmente, de manera inconsciente y cuasautomática, debido a una triple necesidad: para tener la legitimación de la sociedad, para conseguir la protección de sus actividades y por la aspiración de pertenecer al sistema, lo anterior se puede corroborar de nueva cuenta en Hielo negro: 
A las dos y media entró al salón VIP del Blanc des Blancs, sobre Reforma, donde saludó a don Renato, viejo empresario amigo de su papá, quien comía con el secretario del Trabajo. Los viejos invitaron a Lizzy a sentarse con ellos, propuesta que declinó amablemente. Se despidió y caminó hacia su mesa favorita, al fondo del restaurante. Pidió una ensalada de arúgula con carpacio de salmón y vino blanco. Desde el otro lado del restaurante, el secretario particular del procurador general de la República le guiñó un ojo. (Fernández, 2011, pp. 92-93. Las cursivas son mías).

Ante la complicidad y la tolerancia de la clase dirigente, la soberanía del narco-capitalismo conduce a una recodificación de valores, en este sentido Félix Guattari (2004), en su texto Capitalismo mundial integrado..., asevera: "El capital no es racional. Es hegemonista [...] antes que una operación de beneficio, es una operación de poder" (p. 86). Por tal motivo, la narco-economía se caracteriza por ser extremadamente violenta, represora y degradante incluso con el propio sistema político, aspecto que está representado en Fiesta en la madruguera:

Yo la pasé muy bien escuchando las pláticas de Yolcaut y el gober. Pero el gober no [...]. Entonces el gober me preguntó mi edad y cuando se la dije opinó que yo todavía era pequeño para estas cosas. Ahí fue cuando Yolcaut se enojó y le tiró a la cara un montón de dólares que sacó de una maleta. Eran muchos, miles. Y se puso a gritarle: - ¿Cállate, pinche gober, tú qué chingados sabes?, pendejo, toma tu limosna, cabrón, ándale. Al gober se le puso la cara más roja, como si ahora sí fuera a explotarle, pero empezó a reírse. (Villalobos, 2010, p. 27).

En el fragmento anterior se evidencia la subordinación de la clase gobernante al poder que detenta el narcotráfico. Yolcaut, aprovechando esta sumisión, opera con estrictas razones pragmáticas, como un instrumento de servicio y deshecho. En definitiva, como se puede observar en los ejemplos anteriores, el incremento y la expansión del poder económico, por parte de los grandes carteles criminales, genera nuevos aspectos geopolíticos para forzar su integración a las élites dirigentes y sectores dominantes, por supuesto, siempre con el aval del sistema político corrupto, o 
por medio de mecanismos coercitivos que trastocan los códigos del Estado. De este modo, el narcocapitalismo, en primer término, tiene como principal finalidad subvertir los estratos oficiales; sin embargo, siempre busca la legitimación y un status social que proyecte una imagen de nuevo socius.

Ahora, como segundo objetivo, corresponde analizar cuáles son las dinámicas que expone la narconovela para que el tráfico de drogas se instaure como una fuerza molar que busca perpetuarse como un órgano regulador. De hecho, al convertirse en una máquina despótica utiliza elementos represivos como modus operndi para establecer nuevos territorios, pero ante todo evidenciando que el aspecto subversivo o línea de fuga que, en primera instancia manifiesta, es alterado por el flujo de la máquina capitalista.

Sin embargo, en principio, el llamado narco-capitalismo nace de manera informal y subterránea al evadir la inspección legal o fiscal del Estado, estableciendo así inicialmente una línea de fuga. Pero a través de su rápido crecimiento y poder, esta práctica criminal se establecerá poco a poco como una entidad molar, debido al deseo por controlar las máquinas sociales, además de constituirse como un negocio con plusvalía y estabilidad; lo anterior se puede comprobar en la novela de Sergio González Rodríguez (2018), titulada El vuelo:

Vendieron tanta cocaína y marihuana que compraron la cantina donde se originó el negocio. Eran generosos, si les convenía repartían dinero a diestra y siniestra, y Lamberto le dio por ayudar en obras pías, procurar matrimonios y saldar cuentas de viudas. Los políticos comenzaron a buscarle para pedir consejo y las señoras hicieron lo propio para presentarle a sus hijas casaderas. Tasaban los cuerpos vírgenes (p. 14. Las cursivas son mías).

Tal como se observa en el fragmento antes citado, el comercio de drogas, como sistema económico, controla y paulatinamente va adquiriendo una hegemonía territorial absoluta, a partir de la apertura de mercados globales y la acumulación de grandes fortunas. No obstante, como línea de fuga, establece distintos mecanismos para alterar el orden social, ganar nuevos espacios y 
establecer redes de complicidades. Todo ello conlleva a maniobrar con una rápida movilidad para constituirse como un segmento molar.

En la narconovela una línea de fuga que irrumpe, fragmenta y produce desconcierto es la violencia; ésta, en primer orden, desestabiliza frecuentemente la entidad molar que representa el Estado; en Hielo negro, por ejemplo, esta característica sobresale de forma constante: "En lugar de un mensaje al cártel contrario, de las amenazas a la policía o de las advertencias entre narcos, en medio de los doce cadáveres con tiro de gracia hay una carita feliz con un mensaje garrapateado con spray en la pared: HAVE A NICE DAY!!!"(Fernández, 2011, p. 18). El acto en sí mismo representa, para quien ejecutó a los doce sujetos, una burla que paradójicamente altera el significado de los propios acontecimientos. En este sentido, podemos afirmar que la leyenda del mensaje rompe, vulnera y descontrola a la máquina represora, en este caso, encarnada por la policía.

Así, la violencia es una clara consecuencia del poder y control económico que detentan los cárteles de la droga. La representación que se hace de ella en la narcoficción, generalmente reproduce la misma narrativa discursiva que incansablemente los medios de comunicación emiten, pues pareciera que, para la sociedad, el asombro o el temor que puede generar, ya se ha normalizado, pues en palabras de Fernando Reaiti (1992) el artificio estético también la suele trivializar:

En Violence in the Arts un estudio sobre las representaciones artísticas de la violencia moderna, John Fraser propone que en nuestra época ha aumentado el nivel de aceptación de la violencia, y el umbral de tolerancia del público ante ella se ha elevado. [...] De allí que el artista que desea representar la violencia corra el peligro de convertirla en un recurso estético más, sin verdadera conexión con la experiencia del lector, y de allí también que la reiteración de situaciones violentas tienda a banalizarlas. (p. 33).

De esta forma, se pude afirmar que la normalización de la violencia, tanto en los sectores sociales como en el plano estético, es producto de una puesta en escena que representa dos visiones o perspectivas: Nosotros/Otros, esta dicotomía se traduce en una despreocupación e indiferencia por 
el cuerpo ajeno: muerto, mutilado, impedido, desechado, aspectos que Mbembe (2006) considera forman parte de una dinámica impuesta desde los aparatos del poder para administrar la muerte.

Ante todo, la violencia en el corpus de análisis se torna una singular representación del esquizo, que, acorde con Deleuze y Guattari (2002), subvierte los flujos impuestos por el socius, quien sólo quiere controlar y reprimir los deseos; sin embargo, a partir del segmento de fuga se posibilita la emanación de contraflujos; como ejemplo nuevamente citamos la novela Hielo negro, en la que los actos violentos se convierten en un performance:

A las diez comenzó la proyección. Los invitados observaron asombrados las pantallas. En los monitores se podía ver una grotesca coreografía. Un grupo armado de personas disfrazadas aterrorizaba a un grupo de custodios. Todo había sido grabado cámara en mano. La imagen saltaba y los hechos se volvían confusos. Pero la matanza brutal era clara para los asistentes. Alguno de ellos se conmovió hasta las lágrimas. Uno más incluso de acercó hasta Lizzy, quien bebía discretamente en una esquina, para susurrarle en el oído: ---Es una pieza hermosa. ---Eso es lo más hermoso que me han dicho nunca---murmuró la artista ante el galanteo. (Fernández, 2011, pp. 171-172)

Para Lizzy Zubiaga la violencia adquiere otra dimensión, ella la visualiza como una expresión "artística", en la cual la imagen y la atmósfera que rodea el acontecimiento, trastoca el significado de las máquinas represoras. Los fragmentos anteriores, en Hielo negro, demuestran que la violencia genera nuevas maneras de alterar el control del socius. Pero, ante todo, generar puntos de fuga que rompan con lo troncal y se desplieguen de forma rizomática.

Es importante apuntar que la violencia nunca es resultado de una elección aleatoria porque generalmente presenta razones de carácter instrumental, con un propósito específico, nunca son actos aislados, son producto en la mayoría de los casos de un afán de exhibicionismo, de mostrarse como un hecho de poder. En síntesis, la violencia es una escenificación que contiene un sentido o significado concreto, que en ocasiones se representa como, acabamos de ver en la novela Hielo negro, un espectáculo; en otros contextos se produce de manera colectiva, disponiendo una serie 
de prácticas públicas como las ejecuciones, los linchamientos, las humillaciones, pero en ambos casos se presenta como un performance de terror y de necropoder.

Bajo estas arraigadas prácticas de asesinar, desechar y censurar, el narcotráfico se torna rápidamente una figura rígida. De manera metódica fija sus códigos, delimita su territorio, evitando el desorden y cualquier aspecto que provoque desestabilidad. Si en principio, como ya ejemplifiqué con antelación, representa una línea de fuga, muy pronto por su naturaleza coercitiva se convierte en una entidad molar. Pero para erigirse como nueva máquina represora primero tiene que establecer líneas moleculares que romperán la hegemonía, este rasgo lo podemos hallar en la novela La prueba del ácido al sellarse un pacto entre distintos cárteles para crear un nuevo grupo que se convertirá en un nuevo socius:

El asunto es que la idea de Samantha de negociar es una pendejada, necesitamos huevos en el mando y el que los tiene es Eloy Quintana. Yo estoy con usted, don Eloy. Y yo. Todos eran su gente. Se separarían del cártel y harían su grupo, engancharían a los gringos necesarios y darían la pelea, en unos años serían los más poderosos. Quintana explicó con amplitud y ambición su programa: Todo Sonara sería suyo, además de las plazas que ellos representaban. (Mendoza, 2010, p. 225).

Sin embargo, a partir de distintos mecanismos, como mantener los mercados, entablar alianzas, castigar las deslealtades (pequeñas líneas moleculares que de inmediato son contenidas), corromper autoridades y reterritorializarse, se ejerce el control absoluto sin menoscabo. Así se convierte en una máquina absolutista que ante todo tiene como propósito cristalizarse como única entidad de poder, para ello actúa, ejecuta y elimina; todo lo anterior se presenta, de nueva cuenta en La prueba del ácido, como respuesta a la traición-de nueva cuenta se observa el espectáculo de la violencia-:

El convoy de los jefes tomó la carretera a Culiacán. En posición protegida la Hummer de Eloy Quintana, el nuevo capo de la región. Avanzaban a nueva velocidad. En el entronque para la urbanización Nuevo Altata, se les apareció el diablo. Dos vehículos les enviaron bazucazos de frente, además de dos de la retaguardia, [...] Samantha Valdés, vestida de 
negro, con el pelo recogido, los alcanzó [...]. Disparó tres veces. Quintana se sacudió. (Mendoza, 2010, p. 227).

El fragmento anterior demuestra que pese a los rompimientos moleculares que se puedan generar al interior de un cártel, el socius controla, reprime y sanciona, dejando de manifiesto su hegemonía, tornándose como una fuerza inamovible que elimina todo aquello que aspira a ocupar su sitio e impide que cualquier línea de fuga o molecular fragmente su poder y control. También se evidencia que los códigos establecidos son inmóviles y todo aquel que los infrinja será eliminado porque los diversos mecanismos de la máquina limitan los trazos territoriales y cualquier flujo o resistencia que obstaculice su estabilidad.

Una constante en la narcoficción mexicana es representar la violencia desde la perspectiva del victimario, nunca de la víctima. Siempre desde la posición del poder perpetrador; por tal razón, siempre se justifica o se legitima la crueldad, el terrorismo o la muerte, como parte de una validación ante sus pares. Mediante la constante ejecución de acciones violentas, la certeza de poder sobre otros y el incremento de bienes económicos a partir de medios represivos, los cárteles criminales en poco tiempo alcanzan un de empoderamiento y estatus social sobresaliente. En consecuencia, el narcotráfico se constituye como una entidad necropolitica en el espacio social, sustituyendo el papel que tradicionalmente ha tenido el Estado como represor y asesino de sus propios ciudadanos.

La violencia representada desde la visión del perpetrador es claramente reproducida en la narconovela Conspiración de Víctor Ronquillo (2011). En este relato, el periodista Rodrigo Ángulo es contactado por un extraño personaje del narcotráfico, encargado de ejecutar múltiples atentados de manera sincrónica en distintos puntos de la República:

-Agradezco que nos acompañes, no hubiera querido despertarte tan temprano, pero hay algo que tenías que ver. Acércate, todo salió bien. En la pantalla de la lap miro una comandancia de policía, es en Acapulco, según el letrero que aparece en la parte inferior de la pantalla, indicando además del lugar, la hora en que se realizó la grabación: 7:09 am. Se 
alcanza a escuchar la agitada respiración de alguien, además de un par de voces de quienes lo acompañan: "Todo está listo...fuego", grita un hombre. Luego se escucha la ráfaga de disparos, la seca explosión que rompe los cristales del edificio de dos plantas con un estallido. - No pierdas detalle, que la fiesta sigue... - dice el hombre, con un entusiasmo juvenil. (Ronquillo, 2011, pp. 127-128).

La violencia desde la perspectiva del perpetrador es un espectáculo, el miedo y el terror forman parte de la misma intención: generar el deseo mórbido del espectador, con el propósito de naturalizar o cosificar la violencia a un simple recuento de cuerpos, de cadáveres, crear una narrativa del necropoder, la muerte se vuelve entretenimiento, se sobredimensiona sus alcances. Esta visión se repite, como ya mencioné con antelación, de manera invariable en distintas novelas con temática narco, hay una articulación discursiva semejante entre medios de comunicación y narcoliteratura; pareciera que en ambas direcciones ficción y realidad se entremezclan:

La escalada de violencia: ejecuciones y muertes. Ataques con granadas a dos comandancias de policías, en distintas ciudades, el primer bazukazo a un cuartel militar. Imposible un montaje, la falsificación de las imágenes. Los comandos vestidos de negro, encapuchados, actuaron con la precisión de una acción sincronizada [...] - me indica la puerta con la palma de la mano derecha extendida - Gracias por haber venido tan temprano. El show ha terminado. (Ronquillo, 2011, p. 129).

De esta manera, la violencia que produce el narcotráfico generalmente tiene como intención la puesta en escena, el espectáculo en el espacio público, la exhibición, la notoriedad; en síntesis: la presencia. Así el escenario social está conformado, de acuerdo con Sayak Valencia (2011), por "prácticas gore", en el que la disposición de un consumismo exacerbado y un mercado global propicia que el crimen organizado disponga de diversos mecanismos con el fin de construir un relato que despierte en el espectador morbo, martirio o sufrimiento.

El narcotráfico se caracteriza por promover la masculinidad hegemónica. Desde esta perspectiva, la violencia de cualquier índole se justifica porque está en juego la valentía, así como la 
demostración de poder. Estos factores están relacionados con la intención de dominar, torturar o destruir y se reproducen con el firme propósito de que el espacio público se genere una representación de la muerte, porque el propósito no solo es asesinar, sino llevar a cabo un ritual de sangre y exterminio, una gramática del límite y el exceso: "la imagen muestra los efectos de la explosión, el frente de la guarnición militar semidestruida, los cuerpos de varios soldados sin vida. Cuatro o cinco personas, entre ellos una mujer, se encontraban en el momento y lugar equivocados" (Ronquillo, 2011, p. 128).

Estos imaginarios del terror evidencian una omnipresencia del crimen organizado, pero esta narrativa no solo se puede observar en el espacio público, también forma parte de una constante mediática que satura de violencia explícita los noticieros y los programas que transmite, usualmente hay una intención de provocar miedo o ansiedad en el auditorio, dicha violencia audiovisual siempre justificada con el argumento de que es información de interés común:

-Buenas noches, el tema de la violencia es recurrente. Tenemos para usted imágenes exclusivas de los ataques en contra de las comandancias de Acapulco, Guerrero, Ahome, Sinaloa y Cuernavaca, Morelos. Para comentar estas imágenes nos acompaña Rodrigo Ángulo, aquí tenemos el crudo reporte, el recuento de los daños, la bitácora de los muertos del día... (Ronquillo, 2011, p. 211).

Por supuesto la narrativa mediática siempre trata de magnificar la violencia, de representar una dinámica de realidad/ficción; es decir, los límites entre los acontecimientos reales y la interpretación de los mismos siempre son imprecisos debido a que las líneas de demarcación no son claras. De manera similar, la función del estado ante el narcotráfico está descentrada, siempre queda relegada porque el crimen organizado se caracteriza por ser omnipotente, justo este vacío provoca que la violencia sea estructural y que el poder de los grupos criminales se vuelva fáctico e impenetrable. Así se puede observar en la novela Contrabando, cuando un comando armado llega y ejecuta a pobladores de Santa Rosa de Uruachi sin ningún impedimento: 
Los judiciales de la Federal, o quienes hayan sido, porque a estas alturas no se pude saber si fueron narcos con credenciales de la Judicial o judiciales con fachas de narcos, llegaron a la plaza, bajaron de su camioneta, sacaron sus pistolas y sus cuernos de chivo, rodearon a la gente que divisaba el baile o que daba vueltas al quiosco y preguntaron por los fugitivos. No hemos visto a nadie. Si alguien se les perdió, búsquenlo, les dijo el Chelelo [...] Ahí mismo lo acribillaron con una ráfaga de metralleta. Tocaron una puerta lateral de la iglesia y cuando el cura salió lo agarraron a cachazos y lo dejaron tirado en el suelo. En la sacristía mataron al forastero que estaba escondido debajo de una cama y en la escalinata del altar al otro, que intentó escapar. (Rascón, 2008, p. 87)

De acuerdo con el planteamiento de la novela Contrabando, la violencia perpetrada por los sicarios del narcotráfico se produce bajo un contexto de absoluta impunidad, porque precisamente el estado ha sido subordinado por el poder económico y el brazo armado de los cárteles criminales. Conjuntamente va creando un itinerario del terror, a partir de ejecuciones, cuerpos, cadáveres, todos estos factores están plenamente inoculados en el imaginario colectivo y social de la población. En consecuencia, como bien apuntan Rodríguez Blanco y Mastrogiovanni (2018):

Crimen "organizado" es una expresión que no solo exime al estado de toda responsabilidad en la generación de violencia, sino que justifica todas las acciones violentas emprendidas por el estado (incluso hasta el grado de poner en peligro a la sociedad, como la toma de ciertas ciudades por parte del ejército) en pos de defender la seguridad nacional. ( $p$. 101).

Ante un estado debilitado, los cárteles criminales ejercen una violencia de la muerte, generando en el ánimo de la población una especie de trauma social permanente, alterando el orden y la convivencia colectiva. Esta dinámica se puede observar de nueva cuenta en Contrabando: "La muerte llegó a Santa Rosa y ya no quiere irse. Fuimos al río a pescar y la muerte fue también, pero no llegó navegando a través de la corriente, sino por el aíre, volando" (Rascón, 2008, p. 97). Esta 
percepción pesimista se relaciona con un espacio público controlado por el crimen organizado y regido por un sistema necropolítico.

\section{Conclusiones}

En conclusión, en las presentes narconovelas analizadas se pudo comprobar que el narcocapitalismo ha debilitado la fuerza y el control del Estado. De esta forma, su poder quedar desplazado [desterritorializado] a través del peso y la presencia de la narcoeconomía, la cual se constituye como una actividad trasnacional que suprime la soberanía de cualquier marco o entidad reguladora gubernamental. Tanto en Hielo negro, Fiesta en la madriguera, El vuelo como en La prueba del ácido se pudo constatar que la violencia, la corrupción y los recursos monetarios son instrumentos que facilitan la protección del sistema político, al amparo de una impunidad ignorada e institucionalizada. Bajo estas circunstancias, los cárteles del narcotráfico van ganando espacios, dominio y hegemonía, convirtiéndose así en una estructura cada vez más sólida, fija y perpetua.

El esquizoanálisis, desde sus preceptos, me permitió comprobar, en las narconovelas examinadas, que el narco-capitalismo va deterritorializando todos aquellos sistemas que impiden su desarrollo. Es un flujo constante que nace como una actividad de ruptura o fuga, incluso, me atrevo a decir, rizomática porque en principio se expande sin lógica, sin orden, se ramifica de manera indiscriminada, pero paulatinamente va adquiriendo estabilidad, firmeza, para instituirse como un segmento molar, el cual va adquiriendo poder y control absoluto sobre la sociedad, los cuerpos policiacos, el sistema político y por supuesto en la economía mundial; es un mercado emergente, global que influye en todos los sectores socioculturales de nuestro contexto histórico y al parecer no tiene fin. Por tal razón, sus métodos e instrumentos de control lo convierten en una nueva máquina despótica que siempre reprime y elimina todo aquello trata de desestabilizarlo.

\section{Referencias}

Deleuze, G. y Guattari, F. (2002). Mil mesetas: capitalismo y esquizofrenia. Trad. J. Vázquez Pérez. Valencia, España: Pre-textos. 
Deleuze, G. y Guattari, F. (1985). El anti-Edipo. Trad. Francisco Monge. Buenos Aires: Ediciones Paidós.

Fernández, B. (2011). Hielo negro. México: Mondadori.

Foucault, M. (2000). Un diálogo sobre el poder. Madrid: Alianza Editorial.

González, S. (2010). El vuelo. México: Mondadori.

Guattari, F. (2004). Plan sobre el planeta. Capitalismo mundial integrado y revoluciones moleculares. Madrid: Traficantes de Sueños.

Mbembe, A. (2006). Necropolítica. Madrid: Editorial Melusina.

Mendoza, E. (2010). La prueba del ácido. México: Tusquets editores.

Rascón, V. H. (2008). Contrabando. México: Planeta.

Ronquillo, V. (2011). Conspiración: la hora del narcoterrorismo. México: Ediciones B.

Rodríguez, S, y Mastrogiovanni, F. (2018). Narrativas hegemónicas de la violencia. El crimen organizado y el narcotráfico entre el periodismo y las ficciones televisivas. Anàlisi. 58, 89-104

Valencia, S. (2011). Capitalismo gore: narcomáquina y performance de género. Hemisphericinstitute.org.

http://hemisphericinstitute.org/hemi/es/misferica-82/triana

Villalobos, J. P. (2010). Fiesta en la madriguera. Barcelona: Anagrama. 